\title{
AVALIAÇÃO DE T\&D: ANÁLISE DE UM CURSO DE CAPACI- TAÇÃO A PARTIR DA PERCEPÇÃO DOS PARTICIPANTES EM UMA INSTITUIÇÃO DE ENSINO SUPERIOR PÚBLICA
}

\author{
T\&D EVALUATION: ANALYSIS OF A TRAINING COURSE FROM THE PERCEPTION OF PAR- \\ TICIPANTS IN A HIGHER PUBLIC EDUCATION INSTITUTION
}

\author{
Gessica Lovato Sório', Naira Teresinha Kaus², Patrícia Nunes Pezzini³, \\ Ana Amélia Zwicker ${ }^{4}$, Luis Carlos Zucatto ${ }^{5}$
}

RECEBIDO EM: 04/11/2017 | ACEITO EM: 29/04/2019

DOI: $10.5902 / 2317175829818$

\section{RESUMO}

O objetivo do artigo foi avaliar os resultados de um curso de capacitação em Metodologia da Pesquisa, realizado na modalidade a distância, a partir da percepção dos participantes, ofertado por uma Instituição Pública de Ensino Superior nos anos de 2015 e 2016 aos servidores docentes e técnico-administrativos em educação. A avaliação foi realizada por meio de uma análise dos documentos referentes ao curso, tais como projetos e relatórios, bem como pelo resultado da Avaliação de Reação aplicada ao final de cada turma com os concluintes. Os resultados sugerem que o curso foi efetivo e gerou benefícios para os servidores capacitados e para a Instituição. Por fim, foi possível identificar algumas oportunidades de melhoria e apresentar recomendações para o aperfeiçoamento das próximas edições.

Palavras-Chave: Treinamento e Desenvolvimento; Avaliação de Treinamento; Avaliação de Reação.

\footnotetext{
1 Mestranda no Programa de Pós-Graduação em Gestão de Organizações Públicas - UFSM.

2 Assistente em Administração na UFSM.

3 Possui graduação em Pedagogia - Licenciatura Plena, pela Universidade Federal de Santa Maria (2012) e MBA em Administraçã̃o e Gestão do Conhecimento pelo Centro Universitário UNINTER (2014).

4 Estuda Doutorado em Administração pelo Programa de Pós-Graduação em Administração (PPGA) da Universidade Federal de Santa Maria (UFSM). Possui Mestrado e Graduação em Administração pela UFSM (2017 e 2008). 5 Possui graduação em Administração pela Faculdade Três de Maio - SETREM (2006), Mestrado em Administracão pela Universidade Federal do Rio Grande do Sul (2009) e Doutorado em Administração pela Universidade Federal do Rio Grande do Sul (2015). Professor Adjunto da Universidade Federal de Santa Maria, Campus Palmeira das Missões e Professor do Programa de Pós-Graduação em Gestão de Organizações Públicas da Universidade Federal de Santa Maria. Coordenador do Curso de Bacharelado em Administração Pública da Universidade Aberta do Brasil/UFSM.
} 


\begin{abstract}
The objective of the article was to evaluate the results of a training course in Research Methodology, conducted in the distance modality, based on the perception of the participants, offered by a Public Institution of Higher Education in the years of 2015 and 2016 to the teaching and technical-administrative servants in education. The evaluation was carried out by means of an analysis of the documents related to the course, such as projects and reports, as well as by the result of the Reaction Evaluation applied at the end of each class with the students. The results suggest that the course was effective and generated benefits for the trained servers and for the Institution. Finally, it was possible to identify some opportunities for improvement and to present recommendations for the improvement of the next editions.
\end{abstract}

Keywords: Training and Development; Training Evaluation; Reaction Evaluation.

\title{
1 Introdução
}

Estamos na Era do Conhecimento, a qual Willerding (2015) caracteriza como uma esfera do conhecimento, do reconhecimento, da compreensão, da experiência, da informação, da interrogativa, submergindo nas descobertas, designando um processo de retroalimentação, em que o conhecimento adquirido é refinado, tornando o indivíduo mais inteligente, sutil, sagaz, inquisitivo e intenso. Dentre as variadas lacunas que devem ser supridas no que se refere ao aprimoramento do conhecimento dos indivíduos, tem-se a responsabilidade das organizações em capacitar os funcionários para o enfrentamento dos desafios laborais, bem como para a consecução de ações de intervenção na realidade local e nacional de uma sociedade. Assim, Gomes Jr (2013) ressalta que é extremamente relevante para as organizações, potencializar o conhecimento individual, de forma que possa ser disseminado na organização, possibilitando a reestruturação de novos saberes.

Deste modo, para que os objetivos e metas de uma organização sejam alcançados de forma sistemática e sustentável, é imprescindível que as pessoas que façam parte dela tenham o domínio de ferramentas, de produtos, de estratégias, de informações, entre outros fatores necessários para a realização de seu trabalho, contribuindo para o crescimento da mesma (RIBEIRO; CONTI, 2015). Além disso, ações que impactem positivamente na sociedade devem ser consideradas nas políticas estratégicas de treinamento das empresas. Desta forma, nos âmbitos público e privado, é importante a realização de ações de capacitação para melhoria do desempenho dos funcionários, repercutindo nos resulta- 
AVALIAÇÃO DE T\&D: ANÁLISE DE UM CURSO DE CAPACITAÇÃO A PARTIR DA PERCEPÇÃO DOS PARTICIPANTES EM UMA INSTITUIÇÃO DE ENSINO SUPERIOR PÚBLICA

dos organizacionais. Para Dias e Guimarães (2016), o capital humano está entre os principais bens constituintes de um modelo organizacional de sucesso, já que é responsável por tornar concreta a atuação da instituição pública ou privada.

Programas de treinamento e desenvolvimento constituem uma das intervenções mais efetivas para melhoraria de desempenho organizacional, tendo em vista que a expansão e a mobilização do portfólio de competências dos funcionários acarretam a ampliação da busca e implantação de soluções para os desafios enfrentados pelas organizações (WILLIAMS; NAFUKHO, 2015). Especificamente, quanto aos treinamentos de pessoal da Administração Pública, Dias e Guimarães (2016) esclarecem que estes tipos de entidades não possuem concorrentes em busca de fatias de mercado, mas existem cidadãos que necessitam de serviços públicos eficazes para a sua sobrevivência e alcance da dignidade social. Desta forma, o fundamental é a criação de valor público.

No que diz respeito ao serviço público, as ações de treinamento realizadas são nomeadas como ações de capacitação e são reguladas por legislações. Assim, entende-se por capacitação o "processo permanente e deliberado de aprendizagem, com o propósito de contribuir para o desenvolvimento de competências institucionais por meio do desenvolvimento de competências individuais" (BRASIL, 2006, p. 1).

As ações de capacitação desenvolvidas na Instituição pesquisada estão em consonância com o Decreto $\mathrm{N}^{\circ}$. 5.707, de 23 de fevereiro de 2006, que instituiu a Política Nacional de Desenvolvimento de Pessoal, a ser implementada pelos órgãos e entidades da administração pública federal direta, autárquica e fundacional. Tal política apresenta como uma de suas diretrizes a avaliação permanentemente dos resultados das ações de capacitação (BRASIL, 2006).

Para Dias e Guimarães (2016), a capacitação profissional é uma arma poderosa na busca pelo desenvolvimento das competências laborais. Assim, o foco em treinamento e desenvolvimento tornou-se indispensável ao alcance da excelência na prestação de serviços.

Diante do acima exposto, no qual se demonstra o caráter estratégico da implementação de ações de treinamento de pessoal, entre as partes constituintes deste processo, evidencia-se a necessidade de avaliar estas ações, a fim de verificar o alcance os resultados. Para Mourão et al. (2014), treinamentos corporativos realizados à distância têm sido cada vez mais frequentes e o desafio de avaliá-los torna-se presente para pesquisadores e profissionais.

Diversos autores conceituam o a avaliação de treinamento e desenvolvimento dos funcionários, entre eles Kirkpatrick (1976); Hamblin (1978); Abbad (1999); ABTD (1999); Kanaane e Ortigoso (2001); Spector (2006); Foltran et al. (2012). Independente da abordagem utilizada, a avaliação adequada dos programas de treinamento e desenvolvimento permite verificar se a ação atendeu aos objetivos traçados.

Para Salvador e Cançado (2013), um dos desafios da avaliação de treinamento consiste em verificar as contribuições desses programas em termos de seus efeitos em níveis distintos. Entre os diversos níveis integrantes dos modelos acima mencionados, esta pesquisa concentra-se na etapa de avaliação de reação dos participantes. 
Diante do cenário de escassez de recursos atualmente vivenciado pelas organizações públicas e privadas, torna-se essencial também avaliar o investimento em capital humano, o qual não está claro para as empresas. Sheehan (2014) problematiza que o investimento em T\&D é altamente sensível à incerteza, especialmente quando considerada no geral. Dada a importância das ações para sustentabilidade organizacional, é absolutamente essencial que o investimento seja sustentado, mesmo na presença de incerteza. A visualização e o tratamento desta ação como investimento, em vez de sua configuração atual de "despesa", pode ajudar a garantir que investimentos deste tipo sejam mantidos. Os profissionais precisam se tornar mais confiantes e competentes em demonstrar que o T\&D é um investimento, com o potencial de gerar retornos significativos para as organizações. E estas incluem tanto instituiç̧̃es públicas e privadas. Assim, Abugre e Adebola (2015) propõem a concentração do treinamento e desenvolvimento na relação significativa entre os resultados e os objetivos do programa das organizações em economias emergentes para o sucesso das mesmas. Ou seja, a avaliação das ações de T\&D.

Considerando-se este cenário, da importância de ações de treinamento e desenvolvimento e de suas respectivas avaliações, tanto em instituições públicas e privadas, o presente estudo foi desenvolvido em uma instituição de ensino superior pública para avaliar a promoção de um curso de capacitação aos servidores docentes e técnico-administrativos em educação nos anos de 2015 e 2016. O curso escolhido foi relacionado à Metodologia de Pesquisa, pois como abordado por Foltran et al. (2012), existem ações que visam a desenvolver conceitos e elevar o nível de abstração das pessoas para que elas possam pensar e agir em termos mais amplos. Ainda, para os autores, o treinamento é considerado um meio de desenvolver competências nas pessoas para que se tornem mais produtivas criativas e inovadoras, contribuindo na produtividade e na motivação dos colaboradores, sendo considerado uma importante ferramenta para as organizações.

Perante a explicação supramencionada, entende-se que a promoção aos servidores de um curso na área de pesquisa - um dos pilares que sustentam os fins das universidades, servindo de conexão com a sociedade - torna-se estratégica, por isso a importância da avaliação de ações deste tipo. Além do mais, a Instituição escolhida, explica em seu Plano de Desenvolvimento Institucional (PDI), que a pesquisa de novos conhecimentos e técnicas científicas no Brasil tem sido historicamente desenvolvida, em sua grande maioria, dentro das Instituições Públicas de Ensino Superior, mais especificamente nas universidades, sendo que as atividades de pesquisa, que sempre estiveram presentes, ganharam destaque especial e relevância crescente dentre as atividades da instituição no decorrer da década de 1990. Desta forma, uma política de pesquisa voltada para o desenvolvimento regional e nacional deve considerar a capacitação dos servidores em relação a este tema, para uma efetiva atuação e intervenção da comunidade acadêmica de forma integrada, com seus alunos, docentes e técnico-administrativos em educação. 
Para Dias e Guimarães (2016), ações voltadas para o treinamento e desenvolvimento de pessoal constituem um campo muito amplo para pesquisas científicas, posto que a busca por constante inovação e melhoria nos processos organizacionais tendem a proporcionar ganhos significativos no cumprimento da missão institucional da organização e no atingimento de seus objetivos. Considerando o exposto, busca-se, por meio deste artigo, avaliar um curso de capacitação em Metodologia da Pesquisa, a partir da percepção dos participantes, ofertado por uma Instituição Pública de Ensino Superior, nos anos de 2015 e 2016, aos servidores docentes e técnico-administrativos em educação.

\section{Referencial Teórico}

Esta seção apresenta o embasamento teórico que orientou a pesquisa.

\subsection{Políticas Públicas}

As políticas públicas apresentam papel essencial na administração pública, como forma de materializar ações para o atendimento das necessidades da sociedade. Conforme Procopiuck (2013, p. 138), a política pública diz respeito "à mobilização político-administrativa para articular e alocar recursos e esforços para tentar solucionar dado problema coletivo".

Políticas públicas são diretrizes elaboradas para enfrentar problemas públicos, são conjuntos de programas, ações e atividades desenvolvidas pelo Estado diretamente ou indiretamente, com a participação de entes públicos ou privados, que visam assegurar determinado direito de cidadania, de forma difusa ou para determinado seguimento social, cultural, étnico ou econômico. A razão para o estabelecimento de uma política pública é o tratamento ou a resolução de um problema entendido como coletivamente relevante (SECCHI, 2013).

Dias e Matos (2012) consideram que as políticas públicas garantem e permitem a gestão do Estado através de um conjunto de princípios, critérios e linhas de ação que têm como objetivo solucionar os problemas nacionais, estabelecendo condições de equidade no convívio social, proporcionando meIhorias na qualidade de vida compatível com a dignidade humana.

Programas públicos, projetos de leis, campanhas publicitárias, esclarecimentos públicos, inovações tecnológicas e organizacionais, subsídios governamentais, rotinas administrativas, decisões judiciais, coordenação de ações de uma rede de atores, gasto público direto, contratos formais e informais com stakeholders são exemplos de políticas públicas (SECCHI, 2013). Estas ações são definidas por meio de normas e regras e materializadas através dos sujeitos sociais e de atividades institucionais, visando à geração de resultados concretos. Assim, é de extrema importância o acompanhamento permanente dos processos pelos quais elas são implementadas e a avaliação constante de seu impacto sobre a situação existente. 
$\mathrm{Na}$ área de Gestão de Pessoas, Terabe e Bergue (2014) consideram que a Política Nacional de Desenvolvimento de Pessoal (PNDP), instituída pelo Decreto n. . 5.707, de 2006, constitui o marco histórico de uma política pública. Tal política será abordada na seção 2.2 do artigo.

\subsubsection{Políticas de Capacitação de Pessoal no Setor Público}

No âmbito da administração pública, Pacheco (2002) afirma que a capacitação permanente dos servidores passou a ser intensificada apenas a partir de 1995. Segundo o autor, o aumento do número de treinamentos acarretou em uma nova perspectiva a respeito do papel da capacitação no setor público, mudando o foco dado apenas aos longos programas de formação, como cursos de especialização e mestrado, e passando a valorizar também os cursos de atualização que visavam à capacitação do servidor para o desempenho profissional.

Com base nas novas concepções na administração pública, em 1998, foi instituída a Política Nacional de Capacitação dos Servidores, por meio do Decreto $\mathrm{n}^{\circ} 2.794$, de $1^{\circ}$ de outubro de 1998 . Sua implementação tinha como finalidade, entre outras coisas, a melhoria da eficiência do serviço público e da qualidade dos serviços prestados ao cidadão (BRASIL, 1998). Entretanto, conforme citado por Pacheco (2002), tal política foi burocratizada e não havia alcançado os resultados esperados até 2002, quanto à divulgação e controle de resultados das ações de capacitação e a racionalização e efetividade dos gastos com capacitação.

Em substituição ao Decreto $n^{\circ} 2.794$, foi publicado o Decreto $n^{\circ} 5.707$, em 23 de fevereiro de 2006, instituindo a Política e as Diretrizes para o Desenvolvimento de Pessoal da administração pública federal direta, autárquica e fundacional. A nova política instituiu algumas inovações quanto à capacitação dos servidores públicos federais. Entre elas, a abordagem da capacitação como um processo contínuo voltado ao desenvolvimento de competências institucionais e individuais e a inclusão da gestão por competências como instrumento da Política de Desenvolvimento de Pessoal. O decreto traz, ainda, como inovação, a possibilidade de obtenção de parâmetros relacionados aos custos das ações de capacitação, contribuindo para o planejamento orçamentário e para uma maior publicidade no processo de capacitação, facilitando a aprovação dos planos sem a ocorrência de distorções na aplicação dos recursos financeiros (MAGALHÃES, 2007).

No que se refere às instituições federais de ensino, mais especificamente aos servidores técnico-administrativos em educação, a Lei $n^{\circ} 11.091$, de 12 de janeiro de 2005, estabelece o Plano de Carreira dos Cargos Técnico-Administrativos em Educação - PCCTAE (BRASIL, 2005). A referida lei contempla a valorização do desenvolvimento do servidor no que diz respeito à capacitação e qualificação estabelecendo a Progressão por Capacitação e o Incentivo à Qualificação.

A Progressão por Capacitação representa a mudança de nível de capacitação decorrente da obtenção, pelo servidor, de certificação em Programa de 
capacitação compatível. Com a mudança de nível, o servidor passa a ganhar um adicional financeiro, fato que pode motivar os servidores a se desenvolverem profissionalmente. Já o Incentivo à Qualificação se dá quando o servidor possui educação formal superior à exigida para o seu cargo, representando um percentual financeiro que varia conforme o cargo e título obtido. Tais medidas, adotadas no decorrer dos anos, demonstram o aumento dos esforços do setor público no que tange à capacitação dos servidores para um melhor desempenho funcional.

Neste contexto, o curso sobre Metodologia da Pesquisa, objeto de estudo do presente artigo, possibilita, por exemplo, que um servidor técnico-administrativo em educação capacitado desenvolva novos conhecimentos, utilize essa certificação para obtenção da progressão por capacitação, e ainda utilize os conhecimentos obtidos no decorrer do curso para elaborar um projeto de pesquisa para ingresso em uma pós-graduação, que ao ser concluída, permitirá a obtenção do incentivo à qualificação. Além disso, os resultados gerados poderão impactar na realidade social.

\subsection{Avaliação de Treinamento e Desenvolvimento}

O treinamento é uma importante ferramenta estratégica no desenvolvimento organizacional, mas para que o treinamento seja eficiente, eficaz e efetivo, é necessário que cada uma das etapas pertinentes a sua consecução seja realizada de forma adequada. Autores como Spector (2006) e Kirkpatrick (2010) definem estas etapas, sendo que, apesar de possuírem denominações diferentes, apresentam basicamente a mesma sequência de ações: Levantamento de Necessidades de Treinamento, Planejamento e Programação, Implementação e Avaliação do Treinamento. Tendo em vista o foco do presente estudo, será abordada a etapa de Avaliação do Treinamento.

Contribuindo para a consolidação do processo de aprendizagem, a avaliação atua como ferramenta facilitadora para apurar os resultados alcançados a partir dos programas de treinamento e desenvolvimento (KANAANE; ORTIGOSO, 2001). Para Hamblin (1978), avaliação é o ato de julgar se o treinamento valeu a pena ou não em relação a algum parâmetro de valor à luz da informação disponível.

A avaliação de um processo de Treinamento e Desenvolvimento (T\&D) permite a comparação dos resultados com os objetivos pré-estabelecidos, determinando sua eficiência e proporcionando o feedback necessário para verificar se a ação executada alcançou as metas determinadas e, até que ponto, ela produziu modificações de comportamentos pretendidos. Spector (2006), afirma que a avaliação é importante, porque muitos programas são ineficientes. Dessa forma, para assegurar que os resultados da avaliação sejam positivos, é importante estar atento ao planejamento e à execução do treinamento.

Kirkpatrick (1976), um dos pioneiros no estudo da avaliação de treinamento, desenvolveu, em 1976, um modelo, que é aceito e comentado até hoje por muitos pesquisadores do assunto. $\mathrm{O}$ mencionado modelo considera quatro níveis a serem avaliados: 
reação - mede as impressões dos participantes do treinamento com relação a conteúdo, instrutores, materiais e recursos utilizados;

aprendizado - avalia o quanto os treinados melhoram ou aumentaram seus conhecimentos, habilidades e atitudes em decorrência do treinamento;

comportamento - identifica se os treinados estão transferindo os novos conhecimentos, habilidades e atitudes para o comportamento no trabalho;

resultados - mede quanto o treinamento afetou positivamente nos resultados do negócio ou contribuiu com os objetivos da empresa.

Posteriormente, diversos autores abordaram a avaliação de programas de treinamento, tais como Kirkpatrick (1976), Hamblin (1978), Abbad (1999), ABTD (1999), Kanaane e Ortigoso (2001) e Spector (2006). O Quadro 1 apresenta um comparativo entre os níveis de avaliação de treinamento propostos por cada um dos autores.

Quadro 1 - Níveis de Avaliação do Treinamento

\begin{tabular}{|c|c|c|c|c|c|c|}
\hline 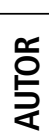 & $\begin{array}{c}\text { Kirkpatrick } \\
\text { (1976) }\end{array}$ & $\begin{array}{c}\text { Hamblin } \\
\text { (1978) }\end{array}$ & $\begin{array}{l}\text { Abbad } \\
\text { (1999) }\end{array}$ & $\begin{array}{c}\text { ABTD } \\
\text { (1999) }\end{array}$ & $\begin{array}{c}\text { Kanaane e } \\
\text { Ortigoso } \\
\text { (2001) }\end{array}$ & $\begin{array}{c}\text { Spector } \\
(2006)\end{array}$ \\
\hline \multirow{8}{*}{$\stackrel{n}{\stackrel{n}{z}}$} & & & $\begin{array}{c}\text { Suporte } \\
\text { organizacional } \\
\text { Características do } \\
\text { treinamento } \\
\text { Características da } \\
\text { clientela }\end{array}$ & & & \\
\hline & $\begin{array}{c}\text { Reacão } \\
\text { Anreadizado }\end{array}$ & Reacão & $\begin{array}{c}\text { Reacoes } \\
\text { Reacos }\end{array}$ & Reação & Reacão & \multirow{2}{*}{$\begin{array}{l}\text { Critério do Nivel } \\
\text { de Treinamento }\end{array}$} \\
\hline & & Aprendizado & Aprendizagem & - & Aprendizagem & \\
\hline & Comportamento & Comportamento & $\begin{array}{c}\text { treinamento no } \\
\text { trabalho }\end{array}$ & Comportamento & Comportamento & \multirow{2}{*}{$\begin{array}{l}\text { Critério de Nível } \\
\text { de Desempenho }\end{array}$} \\
\hline & Resultados & $\begin{array}{c}\text { Efeitos na } \\
\text { Organizacão }\end{array}$ & & Reflexos & Resultados & \\
\hline & & & $\begin{array}{c}\text { Suporte à } \\
\text { transferência }\end{array}$ & & & \\
\hline & & Valores Últimos & & & Performance & \\
\hline & & & & & Potencial & \\
\hline
\end{tabular}

No que diz respeito aos impactos gerados no nível social, Mourão e Borges-Andrade (2013) propuseram um modelo de avaliação de treinamento e desenvolvimento que considere novos indicadores sociais, considerando a crescente demanda para isso. Assim, no estudo, impactos nos níveis individual, organizacional e social foram identificados, mostrando que a maioria das organizações brasileiras mede apenas o nível individual. O impacto social é único e raramente medido por organizações públicas e grandes empresas, onde um departamento de T\&D está em pleno funcionamento.

Independente da abordagem utilizada, a avaliação adequada dos programas de treinamento e desenvolvimento permite verificar se a ação atendeu aos objetivos traçados. Apesar das divergências entre os autores quanto aos níveis para a avaliação de treinamento, percebe-se que estes possuem em comum os níveis de Reação e de Comportamento (ou impacto). 
AVALIAÇÃO DE T\&D: ANÁLISE DE UM CURSO DE CAPACITAÇÃO A PARTIR DA PERCEPÇÃO DOS PARTICIPANTES EM UMA INSTITUIÇÃO DE ENSINO SUPERIOR PÚBLICA

Este artigo aborda a etapa de Avaliação de Reação, a qual é aplicada para todas as ações de capacitação desenvolvidas pela Instituição pesquisada. Cabe destacar que as variáveis que integram esta avaliação são diferentes, considerando-se a modalidade de execução do curso: presencial, semipresencial ou $\mathrm{EaD}$, sendo que o curso analisado foi realizado à distância.

\subsection{A Educação na Modalidade a Distância}

A educação a distância vem transformando o contexto da educação formal e não formal nos últimos anos. A velocidade das informações e as mudanças tecnológicas requerem cada vez mais a adequação dos processos de ensino-aprendizagem frente a esse novo paradigma, incorporando Tecnologias da Informação e Comunicação (TICs) aos processos educativos.

Basicamente, a educação a distância consiste em uma modalidade na qual os alunos e professores estão em diferentes locais geográficos durante todo ou grande parte do tempo em que aprendem e ensinam, dependendo da tecnologia para transmitir informações e realizar interações (MOORE; KEARSLEY, 2007). Para Karpinski et al. (2017), a educação a distância é uma modalidade de ensino que ocorre por meio da interatividade, das atribuições e avanços da tecnologia da informação e comunicação.

Ribeiro e Hirano (2011) destacam como vantagens da Educação a Distância:

a. eficácia - estimula a capacidade do aluno pensar independentemente, trabalhar, se aperfeiçoar e decidir por si;

b. flexibilidade - proporciona a flexibilidade de espaço e tempo;

c. promove a inclusão social - beneficia portadores de necessidades especiais que têm dificuldades de se locomover e que passam a ter a oportunidade de estudar através da modalidade EaD;

d. trabalha a formação permanente e pessoal do aluno - para torná-lo ativo no desenvolvimento de atitudes, interesses, valores, iniciativas e hábitos educativos;

e. promove a democratização do ensino - engloba diversidade econômica, cultural e social;

f. atualização de conteúdos - a atualização e a revisão dos conteúdos programáticos é constante, de forma a proporcionar o melhor aprendizado aos alunos;

g. economia - os valores são menores que os da modalidade presencial de ensino e o gasto com transportes também;

h. novo desafio ao professor - entender as necessidades e capacidades dos alunos, de forma a elaborar ótimos conteúdos, sendo que grande parte destes promovem a interação professor/aluno;

i. abertura - atendimento a um público mais variado e maior que dos métodos presenciais de ensino; 
j. comunicação - utiliza a comunicação multimídia e a comunicação bidirecional, ou seja, comunicação entre ambas as partes;

k. uso de tecnologias - uma das diferenças do ensino presencial do ensino a distância é o uso de novas tecnologias digitais que facilitam o aprendizado superando os limites de tempo e distância.

Além disso, a promoção de cursos a distância possibilita a redução de custos, considerando o atual cenário de crise econômica brasileira. Ainda, colabora-se para a consecução da sustentabilidade ambiental, social e econômica.

No que se refere aos ambientes virtuais de aprendizagem, tal como o Moodle (plataforma na qual foi executado do curso), Vieira e Abreu (2016) apresentam as seguintes vantagens: interação entre o computador e o aluno; a apresentação dos materiais de estudo de modo criativo, atrativo e integrado; a possibilidade de o aluno controlar seu próprio ritmo de aprendizagem, a possibilidade de o professor-tutor dar atenção individual ao aluno, entre outros.

Tratando-se de desenvolvimentos recentes na área da educação à distância, a literatura acadêmica tem considerado o Massive Open Online Course (MOOC) como uma das possibilidades de transformar os atuais cursos do tipo e-learning mais escaláveis, sustentáveis e rentáveis. Segundo Dodson et al. (2015), o termo MOOC, um acrônimo de curso on-line massivo aberto, tem sido quase onipresente em discussões recentes sobre educação on-line e ensino à distância. 0 período de 2014 foi considerado como "o ano do MOOC Corporativo", representando uma grande oportunidade para as corporações impulsionarem essa plataforma de aprendizado relativamente nova e ajustá-la para atender às suas necessidades organizacionais. Os usos potenciais para MOOCs no mundo corporativo são vastos, sendo um deles a expansão das opções de treinamento corporativo. Assim, as instituições públicas brasileiras poderiam considerar estas possibilidades de aplicação no país, por meio da integração de órgãos públicos para a promoção do conhecimento. Esclarece-se que o curso analisado neste estudo não se enquadra nesta modalidade, sendo que, nas considerações finais deste trabalho, sugere-se que a instituição analisada considere deste tipo de ação.

Por fim, independentemente da ferramenta aplicada, pode-se dizer que a educação a distância torna-se uma importante opção para o desenvolvimento de ações de capacitação e qualificação de servidores públicos. Por esta razão, a Instituição Pública de Ensino Superior pesquisada busca incluir em seu Plano Anual de Capacitação diversas ações na modalidade à distância, como é o caso do curso de capacitação em Metodologia da Pesquisa, foco do presente estudo.

\section{Método de Pesquisa}

Na Instituição Pública de Ensino Superior pesquisada, a capacitação dos servidores é feita mediante a execução de diversas ações de treinamento e desenvolvimento oferecidas pelo setor responsável pela Gestão de Pessoas. 
Dentre essas, está o foco do presente estudo, o curso sobre Metodologia da Pesquisa, ofertado aos servidores docentes e técnico-administrativos em educação, nos anos de 2015 e 2016, na modalidade a distância.

Considerando a importância da avaliação permanente das ações de capacitação, o objetivo deste artigo foi avaliar os resultados do curso em questão, a partir da percepção dos participantes. Visando a atender ao objetivo proposto, realizou-se uma pesquisa de natureza descritiva, a qual, de acordo com Matias-Pereira (2012), tem como objetivo descrever as características de uma população ou fenômeno, envolvendo a utilização de técnicas padronizadas para a coleta de dados.

Os dados foram coletados por meio de análise documental e pesquisa de campo. Foram analisados documentos referentes ao curso de capacitação em Metodologia da Pesquisa, disponibilizados pela instituição pesquisada, tais como projetos e relatórios. Além disso, ao final de cada uma das turmas do curso, foi realizada a Avaliação de Reação, com o objetivo de identificar a percepção dos participantes quanto aos seguintes aspectos: conteúdo, instrutor, tutor, interatividade, ambiente virtual de aprendizagem - moodle e aplicabilidade e resultados da capacitação. Tais aspectos foram medidos por meio da aplicação de formulário online estruturado, com questões fechadas, nas quais o respondente deveria atribuir um valor de 0 a 10, escolhendo na coluna "Nível de Satisfação" o número que representasse sua percepção em relação a cada item avaliado, sendo que 0 representava "discordo plenamente" e 10 "concordo plenamente".

Adicionalmente, foram incluídas no instrumento 4 questões abertas, com relação à motivação do servidor para participar de um curso $\mathrm{EaD}$, à relevância da oferta de cursos EaD para servidores da instituição, à contribuição do curso para o desempenho das atividades profissionais na instituição e, ainda, um espaço para sugestões e/ou críticas.

A avaliação de reação foi encaminhada a todos os concluintes, por meio de um formulário online, disponibilizado para a Turma 1 no período de 08 a 28/07/2015 e para a Turma 2 no período de 02/09 a 06/10/2016. O formulário foi respondido por 28 participantes da Turma 1, totalizando $73,6 \%$ dos 38 concluintes, e por 20 participantes da Turma 2, que representam $57,1 \%$ dos 35 concluintes. Com a finalidade de manter o anonimato dos participantes da pesquisa, a identificação dos respondentes foi realizada por meio do sistema alfa numérico, no qual as respostas de cada participante estão representadas pela letra $\mathrm{P}$ e numeradas de forma aleatória.

\section{Apresentação e Discussão dos Resultados}

Nesta seção, são apresentados os resultados em relação a duas edições do curso de capacitação em Metodologia da Pesquisa, ofertado pela Instituição Pública de Ensino Superior pesquisada. 


\subsection{O Curso de Capacitação em Metodologia da Pesquisa}

O planejamento das ações que visam à capacitação e ao aperfeiçoamento dos servidores da instituição pesquisada é realizado com base nas demandas identificadas no Levantamento de Necessidades de Capacitação (LNC) dos Servidores Técnico-Administrativos e Docentes da instituição pesquisada. $O$ LNC é realizado por meio de formulário específico para os TAEs e outro para os Docentes. Para ambos, solicitou-se que no preenchimento do formulário online, indicassem 3 cursos de capacitação diferentes, considerando-se os de maior importância para o desempenho de suas atividades profissionais, observando os objetivos institucionais e as competências a serem desenvolvidas.

O formulário foi disponibilizado a todos os servidores da instituição pesquisada, totalizando 4.497 pessoas, sendo que 2.294 responderam $(51,01 \%)$. Os resultados obtidos subsidiaram as demandas para o ano de 2014, 2015 e 2016.

A promoção do curso de capacitação em Metodologia da Pesquisa se deu em decorrência da alta demanda para este tema, diagnosticada através do LNC, pois o tema Metodologia da Pesquisa foi o oitavo mais solicitado, com 162 solicitações.

Foram promovidas duas turmas do curso, com o objetivo de auxiliar os participantes a elaborarem um projeto de pesquisa, subsidiando-os na continuidade de seus estudos. O planejamento, execução e avaliação foram realizados pelo setor responsável pela capacitação dos servidores da instituição pesquisada. Para cada uma das turmas, foi elaborado previamente um projeto, o qual continha todas as informações acerca do curso a ser realizado, tais como justificativa, objetivo, programa do curso, metodologia, despesa, avaliação e certificação.

No que diz respeito à descrição adequada dos objetivos do aprendizado, Moore e Kearsley (2012) destacam que esta permite, em um curso EaD, o desenvolvimento de um plano de avaliação que irá indicar como o curso será analisado e como o aprendizado será medido. Neste caso, verificou-se que a descrição dos objetivos não foi detalhada, pois apresentou apenas um objetivo geral bem amplo, não contendo objetivos específicos. Desta forma, sugere-se que, para os próximos cursos, a instituição pesquisada reveja este aspecto, adequando o objetivo geral do curso e criando objetivos específicos para possibilitar uma avaliação mais adequada e precisa do projeto. Ainda, podem ser estabelecidas metas para posterior mensuração das ações de execução do curso.

Ambas as turmas tiveram um instrutor e dois tutores, os quais fazem parte do quadro de servidores da instituição pesquisada. A tabela 1 apresenta os dados referentes às duas turmas promovidas.

Tabela 1 - Turmas do curso de capacitação em metodologia da pesquisa

\begin{tabular}{lllll}
\hline Turma & Período & $\mathbf{N}^{\circ}$. de vagas & $\mathbf{N}^{\circ}$. de concluintes & Evasão \\
\hline 1 & $27 / 04 / 2015$ a $07 / 07 / 2015$ & 60 & 38 & $37 \%$ \\
\hline 2 & $06 / 06 / 2016$ a $14 / 08 / 2016$ & 80 & 35 & $56 \%$ \\
\hline Total & 140 & 73 & $48 \%$ \\
\hline Fonte: elaborada pelos autores, a partir dos dados da pesquisa.
\end{tabular}


AVALIAÇÃO DE T\&D: ANÁLISE DE UM CURSO DE CAPACITAÇÃO A PARTIR DA PERCEPÇÃO DOS PARTICIPANTES EM UMA INSTITUIÇÃO DE ENSINO SUPERIOR PÚBLICA

Destaca-se que todas as vagas ofertadas foram preenchidas, entretanto, o número de concluintes apresentou uma taxa de evasão de $37 \%$ na Turma 1 e de $56 \%$ na Turma 2 . A evasão nos cursos de capacitação é uma preocupação constante da instituição pesquisada, que atualmente está analisando a adoção de medidas para minimizá-la. Cabe destacar que a alta evasão nos cursos a distância não se restringe apenas aos cursos de capacitação ofertados para servidores. Um estudo realizado por Conte et al. (2016) apresentou as taxas de evasão dos cursos de graduação e de especialização na modalidade a distância por uma Instituição Pública de Ensino Superior. O estudo apontou que, entre os anos de 2011 a 2014, os cursos de graduação EaD apresentaram uma taxa média de evasão de $50,08 \%$ e os de especialização $34,49 \%$. Assim, percebe-se que o combate à evasão deve ser uma preocupação constante para a promoção de qualquer tipo de curso a distância, tanto para cursos de curta duração quanto para os cursos de educação formal.

O programa do curso contemplou os seguintes temas, os quais foram distribuídos ao longo de dez semanas: "Ciência e Conhecimento; O que é Pesquisa? A escolha do tema; Como interpretar um tema; A construção do problema de pesquisa; Metodologia e Tipos de Pesquisa; e o Projeto de Pesquisa e seus elementos". O curso contou com 2 encontros presenciais, sendo o primeiro na fase inicial, a fim de dar as orientações preliminares e apresentar o ambiente moodle e o segundo ao final do curso.

\subsection{Avaliação de Reação}

Esta seção apresenta os resultados obtidos pela aplicação da Avaliação de Reação aos participantes do curso. Primeiramente, será feita a análise das questões com respostas abertas e, posteriormente, das questões com respostas fechadas.

Ao serem questionados sobre a motivação para participar de um curso $\mathrm{EaD}$, os participantes elencaram, em especial, os seguintes motivos: pela flexibilidade de horários; por não necessitar se ausentar do trabalho; por permitir a participação de servidores lotados em outras cidades; pela indisponibilidade de horário de realizar curso presencial; e por não haver curso presencial disponível para este tema.

Com relação à oferta de cursos EaD para servidores da instituição pesquisada, todos os respondentes concordaram que é relevante, elencando como motivo, alguns dos pontos já citados na questão anterior, conforme se constata na manifestação de alguns participantes:

considero altamente relevante, pois podemos acessar os materiais e as atividades em qualquer lugar e no momento que temos mais tempo para realizá-las. Sem esta modalidade fica muito difícil para os servidores dos campi distantes da sede participarem (P3-Turma1). 
Sim, bastante relevante, devido ao fato de termos atualmente esta ferramenta disponível e que colabora grandemente para o ensino/ aprendizagem com os aspectos da atemporalidade e acesso ao material didático. Em específico aos servidores da instituição, é importante a extensão da plataforma EaD, pois aumenta a possibilidade de participação nos cursos de capacitação sem, necessariamente, comprometer a temporalidade de suas funções (P4-Turma2).

Estas respostas sugerem que o principal fator que motiva os servidores a participarem dos cursos a distância é a flexibilidade de tempo e espaço, descrita por Ribeiro e Hirano (2011) como uma das vantagens da educação a distância.

Ao serem questionados sobre como o curso contribuiu para o desempenho de suas atividades profissionais na instituição, alguns participantes mencionaram a contribuição imediata, pois trabalham diretamente com elaboração de projetos, como se destaca nos trechos a seguir:

minha função requer a elaboração de projetos de pesquisa; logo, o curso contribuiu para que eu aprendesse mais sobre como fazê-lo (P23-Turma1).

O curso contribui positivamente para o desempenho de minhas atividades profissionais, pois estamos elaborando alguns projetos de pesquisa dentro do nosso setor de trabalho (P2-Turma2).

Outros participantes consideraram que a contribuição para a instituição pesquisada não se dará de forma imediata, e sim futura, auxiliando em seu ingresso em uma pós-graduação, a qual irá contribuir para uma maior qualificação do servidor e, consequentemente, para a melhoria do desempenho de suas atividades profissionais na instituição, conforme se verifica no trecho a seguir:

de forma imediata, o curso não contribuiu, porém, terá resultado no momento em que eu for concorrer a um mestrado da instituição e, após concluído o mestrado, aí sim a instituição vai ser beneficiada com a qualificação (P27-Turma1).

Esta afirmação vai ao encontro do estudo de Fortuna (2016) que, ao analisar o impacto da pós-graduação no trabalho, concluiu que os cursos de Mestrado ou Doutorado contribuem para transferência de competências ao trabalho, as quais implicam em mudanças no desempenho laboral e, consequentemente, na organização. Dessa forma, mesmo que o curso não gere impacto imediato, estará trazendo benefícios futuros para a instituição ao auxiliar o servidor a ingressar em um curso de Mestrado ou Doutorado.

Como sugestões e/ou críticas, os participantes elencaram os seguintes pontos: envio de feedback individual para cada atividade, maior carga horária do curso com maior aprofundamento dos temas, oferta de novos cursos sobre a temática (artigos científicos, elaboração de projetos de extensão), ampliação do número de encontros presenciais, e também elogios sobre o curso, parabenizando a equipe. 
Passa-se, agora, à análise das questões fechadas. Para tanto, no Quadro 2 são apresentadas as médias das 33 variáveis da avaliação de reação, que abordaram os seguintes aspectos: conteúdo, instrutor, tutor, interatividade, ambiente virtual de aprendizagem - moodle, e aplicabilidade e resultados da capacitação. No quadro, a Turma 1 está identificada na coluna como T1 e a Turma 2 está identificada como T2. A coluna "média" representa a média aritmética do resultado da avaliação considerando as duas turmas.

Os dados apresentados no Quadro 2 demonstram que, no geral, os participantes estão satisfeitos com os aspectos mensurados pela Avaliação de Reação, pois a média geral das duas turmas foi 8,72 , sendo que individualmente a média da Turma $2(8,81)$ foi levemente superior à média geral da Turma $1(8,63)$.

Com relação à Turma 1, as menores médias obtidas foram nas variáveis "1.3 - Os conteúdos trabalhados foram aprofundados" (média de 7,40) e "1.10 A carga horária do curso foi adequada" (média de 7,70). Estes resultados vão ao encontro das sugestões expostas pelos participantes com relação à necessidade de uma maior carga horária do curso e maior aprofundamento dos conteúdos. Observou-se que, na Turma 2, os participantes apresentaram uma satisfação maior com relação à variável relacionada à carga horária, passando de 7,70 para 8,70. Destaca-se que ambas as turmas apresentaram a mesma carga horária, entretanto, acredita-se que este resultado superior possa ser resultado de um melhor aproveitamento da carga horária pelo instrutor da Turma 2.

Quadro 2 - Médias da Avaliação de Reação

\begin{tabular}{|c|c|c|c|}
\hline \multirow{2}{*}{ ASPECTOS AVALIADOS } & \multicolumn{3}{|c|}{ NIVEL DE SATISFAÇÃO } \\
\hline & T1 1 & $\mathrm{~T} 2$ & Média \\
\hline 1. CONTEÚDO & 8,42 & 8,75 & 8,59 \\
\hline 1.1 A seleção do conteúdo e temas abordados foi adequada. & 8,50 & 8,85 & 8,68 \\
\hline 1.2. Os conteúdos foram compatíveis com os objetivos do curso. & 8,80 & 8,95 & 8,88 \\
\hline 1.3. Os conteúdos trabalhados foram aprofundados. & 7,40 & 8,00 & 7,70 \\
\hline 1.4. A linguagem utilizada no material didático disponibilizado estava clara. & 8,10 & 8,75 & 8,43 \\
\hline 1.5. O material didático disponibilizado estava atualizado. & 8,50 & 8,80 & 8,65 \\
\hline 1.6. A forma como o conteúdo foi estruturado facilitou a aprendizagem. & 8,60 & 8,55 & 8,58 \\
\hline 1.7. O material didático foi disponibilizado conforme o cronograma previsto. & 9,20 & 9,10 & 9,15 \\
\hline 1.8. 0 cronograma inicial do curso foi cumprido. & 9,20 & 9,05 & 9,13 \\
\hline 1.9. A duração do curso foi apropriada para contemplar o conteúdo. & 8,20 & 8,70 & 8,45 \\
\hline 1.10. A carga horária do curso foi adequada. & 7,70 & 8,70 & 8,20 \\
\hline 1.11. o nível de exigência do curso foi adequado aos seus objetivos. & 8,40 & 8,75 & 8,58 \\
\hline 2. INSTRUTOR(ES) & 8,68 & 8,90 & 8,79 \\
\hline 2.1. 0 instrutor possuía domínio dos conteúdos abordados. & 9,10 & 9,30 & 9,20 \\
\hline 2.3. 0 instrutor utilizou estratégias de ensino adequadas aos conteúdos abordados. & 8,60 & 9,20 & 8,90 \\
\hline 2.2. 0 instrutor apresentou os conteúdos do curso com clareza. & 9,00 & 8,75 & 8,88 \\
\hline 2.4. 0 instrutor utilizou casos reais nas atividades propostas. & 8,20 & 8,45 & 8,33 \\
\hline 2.5. 0 instrutor utilizou recursos multimídia e demais ferramentas para facilitar a aprendizagem. & 8,50 & 8,80 & 8,65 \\
\hline
\end{tabular}




\begin{tabular}{|c|c|c|c|}
\hline 3. TUTORES & 8,68 & 9,06 & 8,87 \\
\hline 3.1. 0 tutor possuía disponibilidade para orientação e acompanhamento online. & 8,70 & 9,00 & 8,85 \\
\hline 3.2. 0 tutor esclareceu dúvidas e questionamentos apresentados pelos alunos. & 8,80 & 9,10 & 8,95 \\
\hline 3.3. 0 tutor estimulou a participação individual e grupal no curso. & 8,70 & 9,20 & 8,95 \\
\hline 3.4. 0 tutor realizou o feedback das atividades enviadas pelo aluno. & 8,00 & 8,50 & 8,25 \\
\hline 3.5. 0 tutor foi atencioso e educado no relacionamento com os alunos. & 9,20 & 9,50 & 9,35 \\
\hline 4. INTERATIVIDADE & 8,76 & 8,70 & 8,73 \\
\hline $\begin{array}{l}\text { 4.1. Foram disponibilizadas ferramentas que promoveram a interação durante o curso (chats e } \\
\text { fóruns). }\end{array}$ & 9,10 & 9,10 & 9,10 \\
\hline 4.2. Os recursos disponibilizados favoreceram a comunicação. & 9,00 & 9,05 & 9,03 \\
\hline 4.3. A interação tutor/aluno foi satisfatória. & 8,90 & 9,00 & 8,95 \\
\hline 4.4. A interação aluno/aluno foi satisfatória. & 8,00 & 7,60 & 7,80 \\
\hline 4.5. A articulação da equipe pedagógica (instrutor/tutor) foi satisfatória. & 8,80 & 8,75 & 8,78 \\
\hline 5. AMBIENTE VIRTUAL DE APRENDIZAGEM MOODLE & 9,03 & 8,80 & 8,92 \\
\hline 5.1. A apresentação inicial do ambiente virtual de aprendizagem (AVA) foi satisfatória. & 8,80 & 8,85 & 8,83 \\
\hline 5.2. O ambiente funcionou adequadamente com relação ao acesso ao curso. & 9,00 & 8,70 & 8,85 \\
\hline 5.3. A navegação no ambiente foi realizada com sucesso. & 9,20 & 9,05 & 9,13 \\
\hline 5.4. As ferramentas e recursos disponíveis no ambiente foram utilizadas sem dificuldades. & 9,10 & 8,60 & 8,85 \\
\hline 6. APLICABILIDADE E RESULTADOS & 8,47 & 8,67 & 8,57 \\
\hline 6.1. Assimilação dos conteúdos transmitidos no curso. & 8,50 & 8,65 & 8,58 \\
\hline 6.2. Aplicabilidade dos conteúdos do curso para o desempenho das atividades. & 8,50 & 8,70 & 8,60 \\
\hline 6.3. Capacidade de disseminação imediata dos conteúdos transmitidos no curso. & 8,40 & 8,65 & 8,53 \\
\hline MÉDIA GERAL & 8,63 & 8,81 & 8,7 \\
\hline
\end{tabular}

Fonte: elaborado pelos autores, a partir dos dados da pesquisa.

Ao se analisar as menores médias da Turma 2, verifica-se que estas foram relativas às variáveis "4.4 - A interação aluno/aluno foi satisfatória" (média de 7,60) e "1.3 - Os conteúdos trabalhados foram aprofundados" (média de 8,00). A variável 4.4 apresentou uma média inferior à obtida na Turma 1, passando de 8,00 para 7,60, assim, percebe-se que a interação entre os alunos foi inferior nesta edição. Para Mattar (2002), a interação dos participantes motiva os alunos, reduz a sensação de isolamento, auxilia no desenvolvimento de senso crítico e no trabalho em equipe, contribuindo para o aprendizado. Desta forma, verifica-se a necessidade de criar atividades para apoiar a interação entre o grupo, tais como fóruns de discussão, trabalhos em grupo ou atividades nas quais um aluno avalia as atividades e contribuições dos outros, etc.

Com relação à variável 1.3 , nota-se que apesar de esta apresentar uma melhora com relação à média da Turma 1, destaca-se como uma das menores médias obtidas. Portanto, para próximas edições, sugere-se que o conteúdo do curso seja mais aprofundado pelo instrutor.

Para a Turma 1, as maiores médias obtidas (médias de 9,2) foram encontradas em 4 variáveis: "1.7 - O material didático foi disponibilizado conforme o cronograma previsto"; "1.8 - O cronograma inicial do curso foi cumprido"; "3.5 - O tutor foi atencioso e educado no relacionamento com os alunos"; "5.3 - A navegação no ambiente foi realizada com sucesso". A boa avaliação dos participantes nestes quesitos é fator que indica a execução da capacitação de forma 
satisfatória, tendo em vista a importância do material didático, da plataforma, do instrutor e da correta execução do cronograma quando se trata de um curso a distância. No que diz respeito à relação tutor e aluno, Vieira e Abreu (2016) demonstram a necessidade de constante aperfeiçoamento dos tutores num curso à distância a fim de desempenhar o papel de mediador pedagógico do processo de ensino aprendizagem. Os autores ressaltam a importância da comunicação como mediadora no processo de ensinar e aprender: o foco está centrado na interação e no diálogo entre o professor e o aluno e entre os próprios alunos, pois estes aspectos são considerados fundamentais para o processo educativo. São eles que permitem que o aprendizado ocorra por meio da construção coletiva, uma vez que os momentos de interação são permeados de questionamentos, problematizações, discussões, dúvidas que oportunizam a reflexão, a transformação e a construção de novos conhecimentos. No que se refere aos ambientes de aprendizagem, os mencionados autores esclarecem que estes proporcionam a comunicação dialógica entre os atores envolvidos no processo educativo, facilitando a interatividade e a construção coletiva de novos saberes.

No que diz respeito às menores médias da Turma 1, tem-se: "os conteúdos trabalhados foram aprofundados", com média 7,4 e "a carga horária do curso foi adequada", com média 7,7. Acredita-se que o não aprofundamento do conteúdo pode ter sido causado pela caracterização da carga horária do curso, a qual recebeu a segunda menor nota.

Já com relação às maiores médias da Turma 2, destaca-se a afirmativa "3.5 - O tutor foi atencioso e educado no relacionamento com os alunos", com uma média de 9,50. Esta também foi uma das variáveis com maior média na Turma 1, e consequentemente, foi o aspecto melhor avaliado considerando a média das duas turmas. Isto demonstra que todos os tutores foram atenciosos e educados no relacionamento com os alunos. Isto é de extrema importância para o sucesso de um curso EaD considerando o papel social do tutor, que deve possuir um grau de inteligência interpessoal elevado, conforme descrito por Mattar (2012), no sentido de promover o contato inicial com a turma, incentivar a apresentação dos alunos, enviar mensagens de agradecimento, fornecer feedback, mantendo um tom amigável e gerando um senso de comunidade na turma.

Com relação às menores médias da Turma 2 , verifica-se que o aprofundamento do conteúdo também ficou entre os itens com resultado menor $(8,0)$, perfazendo a segunda posição. $O$ item mais mal avaliado foi em relação à interação aluno/aluno, com 7,60. Sugere-se que a equipe promotora considere estratégias que estimulem a interação dos alunos nas próximas edições, tendo em vista a importância deste tipo de comunicação em um curso à distância, tal como ressaltam Vieira e Abreu (2016), aludindo a um processo de construção coletiva, sendo o aluno um ator ativo e não um mero receptor de informações.

A segunda maior média da Turma 2 foi com relação à variável "2.1 - O instrutor possuía domínio dos conteúdos abordados", com resultado de 9,30, levemente superior à média obtida na Turma 1 para esta variável $(9,10)$. Isto denota 
que os instrutores selecionados para este curso pela instituição pesquisada apresentam qualificação adequada para o desenvolvimento da temática proposta.

A análise da média geral das categorias sugere que a maioria destas apresentou uma pequena elevação na média da Turma 2, comparando-se à Turma 1, exceto com relação às categorias 4 "Interatividade", que permaneceu praticamente com a mesma média; e 5 "Ambiente Virtual de Aprendizagem - Moodle", que reduziu levemente. Esta elevação geral nas notas é um indicativo de um processo de melhoria contínua da capacitação, sendo uma das possíveis explicações a consideração da equipe promotora dos cursos das respostas das avaliações dos participantes da Turma 01 para o planejamento da turma seguinte. Este resultado ratifica a importância da avaliação das ações de treinamento nas Instituições para aperfeiçoamento das mesmas.

\section{Considerações Finais}

A avaliação de Programas de Treinamento e Desenvolvimento é uma etapa essencial para verificar se os objetivos propostos foram atingidos e se os recursos investidos retornaram em benefícios para a instituição. Assim, o objetivo do presente artigo foi avaliar os resultados de um curso de capacitação em Metodologia da Pesquisa, a partir da percepção dos participantes, ofertado por uma Instituição Pública de Ensino Superior, nos anos de 2015 e 2016, aos servidores docentes e técnico-administrativos em educação. Os resultados do estudo possibilitaram identificar alguns problemas e apresentar recomendações para o aperfeiçoamento das próximas edições do curso, que serão apontados a seguir.

Primeiramente, cabe observar que houve dificuldade em mensurar o alcance do objetivo geral estabelecido para o curso, pois este foi muito amplo e não foram estabelecidos objetivos específicos. Dessa forma, sugere-se que, nas próximas turmas, o objetivo geral seja revisto e sejam criados objetivos específicos para uma avaliação mais adequada, os quais podem ser associados a metas para posterior mensuração.

A principal motivação que levou os servidores a participarem de um curso EaD foi a flexibilidade de tempo e espaço. Além disso, todos os respondentes da Avaliação de Reação concordaram que é relevante a oferta de cursos EaD para servidores. Portanto, considera-se oportuno que o órgão responsável pelas ações de capacitação nesta Instituição continue investindo em capacitações nesta modalidade.

Conforme a percepção dos participantes, o curso contribuiu para a instituição de duas maneiras: para alguns servidores, proporcionou a aplicação imediata das competências adquiridas para o desempenho da função de trabalho; já, para outros, o curso auxiliou-os no ingresso em um curso de Mestrado e Doutorado, que trará uma maior qualificação do servidor e, consequentemente, a melhoria do desempenho de suas atividades profissionais na 
AVALIAÇÃO DE T\&D: ANÁLISE DE UM CURSO DE CAPACITAÇÃO A PARTIR DA PERCEPÇÃO DOS PARTICIPANTES EM UMA INSTITUIÇÃO DE ENSINO SUPERIOR PÚBLICA

instituição, possibilitando ainda, ao servidor qualificado, um ganho financeiro previsto no plano de carreira.

Como sugestões, os participantes elencaram os seguintes pontos: envio de feedback individual para cada atividade, maior carga horária do curso com maior aprofundamento dos temas, oferta de novos cursos sobre a temática e ampliação do número de encontros presenciais. Cabe ao órgão promotor dos cursos da instituição pesquisada comunicar aos próximos instrutores/tutores sobre a importância do envio do feedback, bem como analisar a possibilidade de atendimento das demais sugestões.

Quanto às variáveis mensuradas na avaliação de reação, verificou-se que estas apresentaram médias elevadas, demonstrando que, no geral, os participantes estão satisfeitos com os aspectos avaliados para ambas as turmas, as quais apresentaram resultados convergentes, quando comparadas entre si. Como pontos a serem melhorados para próximas turmas, sugere-se que se amplie a carga horária do curso, permitindo um maior aprofundamento dos conteúdos trabalhados e que se promova atividades que incentivem a interação aluno/aluno, tais como fóruns de discussão, trabalhos em grupo, etc.

Por fim, pode-se concluir que o curso gerou benefícios para os servidores capacitados e para a Instituição. As sugestões de melhoria apresentadas visam a aprimorar mais ainda o desempenho do curso, que foi considerado bastante satisfatório.

Em relação a estudos futuros, sugere-se considerar também os outros níveis de avaliação de treinamento, a fim de identificar os impactos no desempenho do servidor e mensurar se o curso trouxe benefícios para a instituição. O impacto social das ações de capacitação promovidas aos servidores pela Instituição também necessita ser aferido, bem como a efetividade dos conhecimentos gerados na prática da pesquisa dos servidores participantes do curso.

Como limitações deste estudo, destaca-se que o formulário de avaliação de reação utilizado foi o modelo padrão do órgão promotor da Instituição, não permitindo aos pesquisadores a análise de outros aspectos relevantes para avaliação do curso. Dessa forma, não foi possível afirmar, por exemplo, se o curso realmente auxiliou os participantes na continuidade de seus estudos, ou seja, se posteriormente ao curso eles obtiveram êxito no ingresso em algum programa de pós-graduação com o projeto e conhecimentos desenvolvidos ao longo da capacitação. Nesse sentido, sugere-se que o estudo seja ampliado, contemplando esta verificação em estudos futuros. 


\section{Referências}

ABBAD, G. Um modelo integrado de avaliação do impacto do treinamento no trabalho - IMPACT. 1999. Tese (Doutorado) - Instituto de Psicologia, Universidade de Brasília. Brasília, 1999.

ABUGRE, J.B.; ADEBOLA, K. An Examination of Training and Development of Middle Level Managers in Emerging Economies: Evidence from Financial Institutions in Ghana. International Journal of Organizational Analysis, v. 23, ก. 2, 2015.

ASSOCIAÇÃO BRASILEIRA DE TREINAMENTO E DESENVOLVIMENTO/ABTD. Manual de treinamento e desenvolvimento. 3. ed. São Paulo, SP: Makron Books, 1999.

BRASIL. Decreto n. 2.794, de $1^{\circ}$ de outubro de 1998. Institui a Política Nacional de Capacitação dos Servidores para a Administração Pública Federal direta, autárquica e fundacional e dá outras providências. Diário Oficial (da República Federativa do Brasil), Brasília, DF, 1998.

. Decreto n. 5.707, de 23 de fevereiro de 2006. Institui a Política e as Diretrizes para o Desenvolvimento de Pessoal da administração pública federal direta, autárquica e fundacional, e regulamenta dispositivos da Lei no 8.112, de 11 de dezembro de 1990. Diário Oficial (da República Federativa do Brasil), Brasília, DF, 24 de fev. 2006.

Lei n. 11.091, de 12 de janeiro de 2005. Dispõe sobre a estruturação do Plano de Carreira dos Cargos Técnico-Administrativos em Educação, no âmbito das Instituições Federais de Ensino vinculadas ao Ministério da Educação, e dá outras providências. Diário Oficial (da República Federativa do Brasil), Brasília, DF, 13 jan. 2005.

CONTE, B. P.; CORONEL, D. A., BENDER FILHO, R. Análise de eficiência dos cursos a distância da Universidade Federal de Santa Maria (2011-2014). Revista Observatorio de la Economía Latinoamericana, Brasil, 2016. Disponível em: <http://www.eumed.net/cursecon/ecolat/br/16/distancia.html >. Acesso em: 14 dez. 2016.

DIAS, D. M.; GUIMARÃES, M. G. V. Avaliação do Impacto da Capacitação Profissional no Âmbito da Prefeitura de Manaus por meio da aplicação do Modelo Impact. Perspectivas em Gestão \& Conhecimento, João Pessoa, v. 6, n. 1, p. 200-222, jan./jun. 2016.

DIAS, R.; MATOS, F. Políticas públicas: princípios, propósitos e processos. São Paulo: Atlas, 2012.

DODSON, M. N. et al. Possibilities for Moocs in Corporate Training adn Development. Performance Improvement, v. 54, n. 10, 2015.

FOLTRAN, C. U. et al.Treinamento e desenvolvimento de pessoas: O sucesso das organizações. Revista Alumni, v. 1, p. 1, 2012

FORTUNA, A. D. M. C. Avaliação do impacto da pós-graduação no trabalho em uma instituição pública federal - CNPQ. 2016. Dissertação (Mestrado em Educação em Ciências). Universidade Federal do Rio Grande do Sul. Porto Alegre, 2016.

GOMES JR, W. V. Gestão do conhecimento e mapeamento de competências: um estudo de caso. 2013. 231 f. Dissertação (Mestrado em Engenharia e Gestão do Conhecimento) - Programa de PósGraduação em Engenharia e Gestão do Conhecimento, UFSC. Florianópolis, 2013.

HAMBLIN, A. C. Avaliação e controle de treinamento. São Paul: McGraw-Hill, 1978.

KARPINSKI., J. A et al. Fatores críticos para o sucesso de um curso em EAD: a percepção dos acadêmicos. Avaliação (Campinas), v. 22, n. 2, 2017.

KANAANE, R.; ORTIGOSO, S. A. F. Manual de Treinamento e Desenvolvimento do Potencial Humano. São Paulo: Atlas, 2001.

KIRKPATRICK, D. L. Evaluation of training. In: CRAIG, R. L. Training and development handbook. 2. p. 18.1-18.27. Ed. New York: McGraw-Hill, 1976.

KIRKPATRICK, D. L.; KIRKPATRICK, J. D. Como Implementar Os Quatro Níveis de Avaliação de Treinamento de Equipes. Rio de Janeiro: Editora Senac, 2010. 
AVALIAÇÃO DE T\&D: ANÁLISE DE UM CURSO DE CAPACITAÇÃO A PARTIR DA PERCEPÇÃO DOS PARTICIPANTES EM UMA INSTITUIÇÃO DE ENSINO SUPERIOR PÚBLICA

MAGALHÃES, E. M. Política de treinamento dos servidores técnico-administrativos na Universidade Federal de Viçosa na percepção dos treinados e dos dirigentes da instituição. Dissertação (Mestrado em Administração) - Universidade Federal de Viçosa, Viçosa, 2007.

MATIAS-PEREIRA, J. Manual de metodologia da pesquisa cientifica. 3. ed. - São Paulo: Atlas, 2012.

MATTAR, J. Tutoria e interação em educação a distância. São Paulo: Cengage Learning, 2012.

MOORE, M. G.; KEARSLEY, G. Educação a distância: uma visão integrada. São Paulo: Cengage Learning, 2007.

MOURÃO, L.; BORGES-ANDRADE, J. Impact evaluation of T\&D at the societal level. Journal of Workplace Learning, v. 25, n. 8, 2013.

MOURÃO, L. et al. Avaliação da efetividade e dos preditores de um treinamento a distância em uma instituição bancária de grande porte. R.Adm., São Paulo, v.49, n.3, p.534-548, jul./ago./set. 2014.

PACHECO, R. S. Política de recursos humanos para a reforma gerencial: realizações do período 1995-2002. Revista do Serviço Público, v. 53, n. 4, 2002.

PROCOPIUCK, M. Políticas públicas e fundamentos da administração pública: análise e avaliação, governança e redes de políticas, administração judiciária. Atlas, 2013.

RIBEIRO, F. D. C.; CONTI, L. A importância do planejamento estratégico nas vendas: um estudo de caso na empresa Kaixotelntegrada. Revista Científica FACOL/ISEOL, v. 2, p. 91-106, 2015.

RIBEIRO, C.F.; HIRANO, F. W. P. Educação a distância. Revista Científica da AJES, v.2, n.5, p.1-19, 2011. Disponível em: <http://revista.ajes.edu.br/index.php/RCA/article/view/79/pdf>. Acesso em: 26 nov. 2016.

SALVADOR, R. L. C. D.; CANÇADO, V. L. Impacto de Treinamento no Trabalho: um estudo de caso na Fundação Hemominas. Teoria e Prática em Administração, v. 3 n. 2, 2013.

SECCHI, L. Políticas públicas: conceitos, esquemas de análise, casos práticos. 2. ed. . São Paulo: Cengage Learning, 2013.

SHEEHAN, M. Investment in Training and Development in Times of Uncertainty. Advances in Developing Human Resources, February 2014, v.16, n.1, pp.13-33, 2014

SPECTOR, P. E. Psicologia nas organizações. 2 ed. São Paulo, SP : Saraiva, 2006.

TERABE, C. P. A. R.; BERGUE, S. T. Gestão Estratégica de Pessoas como Política Pública: Estudo de Caso no Ministério da Ciência e Tecnologia. Caderno Estudos em gestão de pessoas no serviço público - Brasília: ENAP, 2014.

VIEIRA, C. M. S.; ABREU, R. M. A. Educação a Distância: uma reflexão sobre a relação professor/tutor e estudante no processo de ensino e aprendizagem. Revista Intersaberes, v. 11, n.23, p.284-303, 2016.

WILLERDING, I. A. V. (2015). Arquétipo para o compartilhamento do conhecimento à luz da estética organizacional e da gestão empreendedora. 2015. 275f. Tese (Doutorado em Engenharia e Gestão do Conhecimento) - Universidade Federal de Santa Catarina, Florianópolis, 2015.

WILLIAMS, R. C.; NAFUKHO, F. M. Technical training evaluation revisited: an exploratory, mixed-methods study. Performance Improvement Quarterly, v. 28, n. 1, p. 69-92, 2015. 